\title{
Análise socioeconômica do perfil dos microempreendedores individuais do Shopping Independência de Santa Maria-RS
}

\author{
Socioeconomic profile analysis of individual microentrepreneurs Shopping Independence \\ Santa Maria-RS
}
Jéferson Réus da Silva Schulz ${ }^{1}$, Bruna Tadielo Zajonz ${ }^{2}$, Marta Fenner ${ }^{3}$ e Andrea Cristina Dörr ${ }^{4}$

\author{
${ }^{1}$ Acadêmico de Ciências Econômicas - UFSM - Email: jefersonschulz@gmail.com \\ ${ }^{2}$ Acadêmica de Ciências Econômicas - UFSM - Email: brunabtz@gmail.com \\ ${ }^{3}$ Acadêmica de Ciências Econômicas - UFSM - Email: martafenner@hotmail.com \\ ${ }^{4}$ Professora Adjunta do Departamento de Educação Agrícola e Extensão Rural do Centro de Ciências Rurais da UFSM - Email: \\ andreadoerr@yahoo.com.br
}

\begin{abstract}
Resumo
O microempreendedor individual é aquele que trabalha por conta própria e se legaliza como pequeno empresário. Observa-se que essa categoria vem crescendo constantemente no Brasil à medida que se abrem novas oportunidades para o empreendimento autônomo. O objetivo deste artigo é analisar o perfil socioeconômico dos microempreendedores individuais do Shopping Independência de Santa Maria-RS após a implantação do MEI. A metodologia utilizada nesta pesquisa baseia-se na coleta de dados primários por meio da aplicação de formulários junto aos lojistas no periodo de 04 a 09 de novembro de 2013. Os resultados indicam que a maioria dos entrevistados é alfabetizada, possui idade de 15 a 69 anos e escolaridade básica completa. Os dados revelam que a qualidade de vida dos individuos melhorou mesmo que suas receitas tenham diminuido e que existe uma considerável divergência de opinião acerca das vantagens e desvantagens de sua transferência para o shopping. Conclui-se que apesar da melhora em seu bem estar social, os microempreendedores reivindicam por mais atenção ao seu estabelecimento de trabalho por parte da prefeitura municipal, cobrando desta maior divulgação do shopping no intuito de aumentar suas vendas.
\end{abstract}

Palavras-chave: Microempreendedor Individual. Economia Informal. Shopping Independência.

\begin{abstract}
The individual micro entrepreneur is self employed and legalized as a small businessman. It is perceived that this is a fast growing business category in Brazil as new autonomous business opportunities raise in the country. The aim of this article is to analyze the socioeconomic profile of micro entrepreneur individuals at Independência Shopping Centre in Santa Maria-RS-Brazil after the implementation of MEI. The methodology utilized in this research was based on primary data gathered from questionnaire assessment applied to store owners from the $4^{\text {th }}$ to $9^{\text {th }}$ November 2013. Results indicate that the majority of participants interviewed were literate, age ranged between $15-69$ years old and have completed fundamental education. The data revealed that individuals' quality of life has improved despite their decreasing profitability, also that there is considerable diverging opinions with respect to the advantages and disadvantages of local shop owners being relocated to the Shopping Centre premises. It was concluded that despite the improvement in shop owners' social well-being, entrepreneurs request more attention to be provided to their work establishment from the administrative Municipal level. Additionally, shop owners claim for more advertisement of the Shopping Centre as an attempt to enhance their own sales.
\end{abstract}

Keywords: Individual Micro Entrepreneur. Informal Economy. Indepenência Shopping Centre. 


\section{Introdução}

É crescente o problema acerca da chamada economia informal que, segundo a Organização Internacional do Trabalho (OIT) (2006, p. 7), "refere-se a todas as atividades econômicas de trabalhadores e unidades econômicas que não são abrangidas em virtude da legislação ou da prática por disposições formais". Conforme a mesma fonte, assim como os trabalhadores assalariados, a maior parte dos trabalhadores que atuam por conta própria são vulneráveis e carecem de segurança. Esses trabalhadores são acometidos pela falta de proteção, de direitos e de representação e frequentemente são atingidos pela pobreza.

Segundo Ulyssea (2006), a rigidez contratual e os custos impostos pela legislação trabalhista são considerados como uma das principais razões para a existência de elevadas taxas de informalidade no mercado de trabalho brasileiro. Ou seja, a legislação trabalhista, tanto na perspectiva dos empregadores quanto para os trabalhadores, têm fortes incentivos à informalidade. Dessa forma, o Fundo de Garantia do Tempo de Serviço (FGTS), o programa de seguro-desemprego e o funcionamento da Justiça do Trabalho, são citados como as principais fontes de distorção dos incentivos.

Nos centros urbanos, uma das formas mais comum de manifestação do trabalho informal é o comércio de rua praticado por camelôs e vendedores ambulantes. Com o objetivo de sanar este problema, a prefeitura de Santa Maria-RS, a exemplo do que ocorrera em grandes capitais como Belo Horizonte, transferiu os camelôs das ruas da cidade para o Shopping Independência, legalizando suas atividades e inserindo este grupo de trabalhadores no Programa Microempreendedor Individual (MEI). Todos aqueles indivíduos que trabalhavam de maneira informal como camelôs de rua, tiveram seu cadastramento no MEI realizado pela própria Prefeitura Municipal para que os mesmos fossem beneficiados pelos direitos garantidos aos microempreendedores individuais formalmente legalizados de acordo com a Lei Complementar $\mathrm{n}^{\mathrm{o}} 128$ de 19 de dezembro de 2008, que criou condições especiais para que o trabalhador conhecido como informal possa se tornar um MEI legalizado.

Microempreendedor individual é a pessoa que trabalha por conta própria e que se legaliza como pequeno empresário (BRASIL, 2013). No entanto, para ser um microempreendedor individual é necessário faturar no máximo até $\mathrm{R} \$ 60.000,00$ por ano e não ter participação em outra empresa como sócio ou titular. O MEI também pode ter um empregado contratado que receba o salário mínimo ou o piso da categoria.

Entre as vantagens oferecidas por essa lei está o registro no Cadastro Nacional de Pessoas Jurídicas (CNPJ), o que facilita a abertura de conta bancária, o pedido de empréstimos e a emissão de notas fiscais. Dessa forma, o MEI se enquadra no Simples Nacional e ficará isento de tributos federais como o Imposto de Renda (IR), o Programa de Integração Social (PIS), a Contribuição Para Financiamento da Seguridade Social (COFINS), o Imposto Sobre Produtos Industrializados (IPI) e a Contribuição Social Sobre Lucro Líquido (CSLL) (BRASIL, 2013).

Desse modo, o empreendedor paga apenas o valor fixo mensal de R $\$ 34,90$ (comércio ou indústria), $\mathrm{R}$ \$ 38,90 (prestação de serviços) ou $\mathrm{R}$ \$ 39,90 (comércio e serviços), que será destinado à Previdência Social e ao Imposto Sobre Circulação de Mercadorias e Prestação de Serviços (ICMS) ou ao Imposto Sobre Serviços de Qualquer Natureza (ISSQN). Essas quantias serão atualizadas anualmente de acordo com o salário mínimo. Por meio destas contribuições, o microempreendedor individual tem acesso a benefícios como auxílio maternidade, auxílio doença, aposentadoria, entre outros (BRASIL, 2013).

Considera-se importante compreender os aspectos ligados à informalidade e tem-se em vista que o incentivo ao empreendedorismo pode atuar como uma forma de reduzir este problema, principalmente no âmbito do comércio dos camelôs e vendedores ambulantes. Dessa forma, o objetivo desta pesquisa consiste em analisar e descrever o perfil socioeconômico dos microempreendedores individuais do Shopping Independência de Santa Maria-RS, abordandose variáveis que caracterizam tanto o perfil do microempreendedor como também do próprio empreendimento. 


\section{Metodologia}

A pesquisa foi realizada no Shopping Independência de Santa Maria-RS, sendo esta caracterizada como um levantamento de campo. Segundo Gil (2008, p. 55), um levantamento de campo "consiste na interrogação direta das pessoas cujo comportamento se deseja conhecer". Neste tipo de pesquisa solicita-se a um grupo significativo de pessoas informações acerca do problema estudado, para que, posteriormente, através de uma análise quantitativa, seja possível obter as conclusões correspondentes aos dados coletados.

Os dados primários foram coletados mediante realização de uma entrevista com o responsável pela organização em estudo e também por meio da aplicação de um formulário junto aos microempreendedores do Shopping Independência. Buscou-se junto a Secretaria de Desenvolvimento Econômico de Santa Maria-RS informações quanto ao número de bancas atuantes e critérios que definem os camelôs, agora lojistas, como microempreendedores individuais.

Para obtenção do tamanho da amostra, considerou-se para fins de cálculo uma população finita de 208 elementos. Para realizar o cálculo da variância $\left(s^{2}=0,04\right)$, empregou-se a variável escolaridade obtida por meio do estudo piloto e um erro amostral de 5,00\%.

A fórmula utilizada para o cálculo da amostra foi a seguinte:

$$
n=\frac{\mathrm{Z}^{2} \times \mathrm{s}^{2} \times \mathrm{N}}{\mathrm{e}^{2} \times(\mathrm{N}-1)+\mathrm{Z}^{2} \times \mathrm{s}^{2}}
$$

onde:

$n=$ tamanho mínimo da amostra calculada;

$Z=$ valor crítico da estatística $\mathrm{z}$ tabelado;

$s^{2}=$ variância obtida pela amostra piloto;

$N=$ tamanho da população;

$e=$ erro amostral, obtido através da amostra piloto.

Calculando-se:

$$
n=\frac{1,96^{2} \times 0,04^{2} \times 208}{0,05^{2} \times(208-1)+1,96^{2} \times 0,04^{2}}=47,62
$$

O cálculo da amostra resultou em 47 microempreenderes, para os quais foi aplicado um formulário durante o período de 04 a 09 de novembro de 2013, contendo 26 perguntas que se distribuíram entre abertas e fechadas, sobre o perfil socioeconômico e características do empreendimento.

Destaca-se também que foi utilizada a técnica de observação participante durante a coleta dos dados. De acordo com Appolinário (2006, p. 139), "esta técnica é aquela na qual o pesquisador, enquanto observa e registra, interage com os sujeitos observados". Dessa forma, é possível que o pesquisador experencie os eventos "por dentro", com se fosse um dos sujeitos.

A tabulação dos dados obtidos foi feita através do programa Microsoft Office Excel 2007. A análise descritiva dos dados permitiu a construção de gráficos e tabelas para facilitar a compreensão dos resultados. 


\title{
3 Referencial teórico
}

\subsection{A economia informal e o comércio de rua}

A economia informal, segundo Bagnasco (1997), pode referir-se aos processos de produção e troca que, de um modo ou de outro, deixam de agir em conformidade com as leis comerciais, fiscais ou trabalhistas. Esta é uma concepção de economia informal na qual podem estar inseridos os camelôs de rua e demais trabalhadores por conta própria, pois geralmente trabalham às margens da legislação.

Kitamura, Miranda e Ribeiro Filho (2007) apontam que a economia informal é um conceito bastante abrangente, sendo o comércio de camelôs e ambulantes a parte mais representativa desse setor. De acordo com Theodoro (2000, p. 7), "[...] o pequeno comércio de rua é uma atividade secular, assim como grande parte dos serviços pessoais, da produção artesanal, etc.". Nesse contexto, surge a figura dos camelôs de rua, que veem nesta iniciativa uma forma de adquirir renda, seja por falta de outras oportunidades ou mesmo por opção, caindo, dessa forma, na esfera do subemprego, uma vez que não atendem a disposições formais.

Cleps (2009) mostra que, na questão ligada ao problema do desemprego, a atividade informal é considerada como uma "válvula de escape", sendo uma alternativa para aqueles que não conseguem se inserir no mercado de trabalho formal. A autora menciona ainda que, "[...] a racionalidade econômica dos empreendimentos ditos populares está subordinada à lógica da manutenção da renda familiar por meio da geração de empregos para indivíduos com pouca qualificação para o mercado de trabalho" (CLEPS, 2009, p. 330).

Para Cacciamali (2000), o trabalho informal está intrínseco a atividades, trabalhos e rendas realizadas que desconsideram regras expressas em leis ou em procedimentos usuais, podendo abranger uma série de fenômenos muito distintos, onde se enquadra, inclusive, o comércio de rua ou ambulante. Ainda segundo a autora, no que concerne ao que denominou "processo de informalidade", ela afirma que decorrem pelo menos dois fenômenos principais associados ao mercado de trabalho, sendo o segundo deles o fenômeno do autoemprego e outras estratégias de sobrevivência. Essas estratégias decorrem do fato de as pessoas apresentarem dificuldades de reemprego ou de ingresso no mercado de trabalho, ou até mesmo por opção, auferindo renda através de formas de trabalho por conta própria ou em microempresas (CACCIAMALI, 2000).

Ao se reportar sobre a análise da categoria trabalhadores por conta própria, Cacciamali (2000, p. 167) afirma que:

\begin{abstract}
No caso da categoria trabalhadores por conta própria, ou formas análogas, como muitos microempresários, desejamos apontar que eles estão criando uma ocupação no mercado de bens, principalmente na prestação de serviços, com o objetivo de se autoempregar. $\mathrm{O}$ que caracteriza esse grupo, especialmente aqueles que operam com baixo nível de produtividade com relação às empresas capitalistas, é que compreende indivíduos com pouco nível de capital físico ou humano, que são simultaneamente patrões e empregados de si mesmos. Trabalham diretamente na produção ou na prestação de um serviço e podem engajar familiares ou ajudantes assalariados nesse processo como extensão de seu próprio trabalho, ou seja, prescindem de mão de obra assalariada permanente para seu funcionamento. A lógica de sua atuação no mercado prende-se à sobrevivência, à obtenção de um montante de renda que lhes permita sua reprodução e de sua família, não tendo como meta explícita a acumulação ou a obtenção de uma rentabilidade de mercado, inclusive porque não possuem nem capitalização nem organização do trabalho que lhes deem sustentação para tais fins [...].
\end{abstract}

Corseuil, Reis e Brito (2013) aludem que, de um modo geral, é possível observar que os trabalhadores do setor informal têm remuneração mais baixa do que aqueles trabalhadores do setor formal e que, dessa forma, existem maiores chances de os informais habitarem domicílios pobres. Para os mesmos autores, a diferença nos rendimentos entre setor formal e informal implica em consequências para o bem-estar da população. É possível atribuir ao trabalho informal um papel central no que diz respeito às condições em que os trabalhadores informais vivem, de forma que estão sujeitos a condições de vida precárias, justamente pela baixa renda que auferem em suas atividades. 
Com a finalidade de sanar o problema da economia informal, entra em ação a figura do Estado ou entidade competente através da formulação e implementação de políticas que visam combater o problema do subemprego, adotando, dessa forma, uma nova postura institucional através de políticas de apoio e incentivo. Conforme salienta Theodoro (2000, p. 8), "a abordagem em termos do setor informal é essencialmente uma perspectiva de intervenção institucional, abrindo um novo campo de ação do Estado". O autor atenta também que o Estado, ao estar em face deste novo campo de ação, [o setor informal], deve desenvolver políticas e programas que sirvam de amparo ao mesmo.

Uma das maneiras de se enfrentar o problema do trabalho informal é o incentivo ao espírito empreendedor. Os trabalhadores e as unidades econômicas da economia informal podem constituir um potencial empresarial, uma vez que dispõem de qualificações variadas (OIT, 2006). Em virtude dessas qualificações é que muitos destes trabalhadores acabam se tornando empreendedores. A promoção do trabalho digno tem por base eliminar os aspectos negativos da informalidade, onde se preconiza o empreendedorismo como forma de incentivo aos trabalhadores para que possam ingressar na economia formal (OIT, 2006).

O Sebrae (2014) define empreendedor como aquele que inicia algo novo, que vê o que outros não veem, que realiza antes, que sai da área do sonho e do desejo e parte para ação. Ainda conforme o Sebrae, "empreender é identificar oportunidades e desenvolver meios de aproveitálas, assumindo riscos e desafios".

Para promoção do trabalho formal em detrimento do informal, deve-se preconizar a importância da geração de emprego e renda, de forma a diminuir os índices de informalidade e promover a inclusão daqueles trabalhadores informais no mercado formal. França Filho (2006) mostra que há duas concepções de políticas de geração de trabalho e renda, as quais, segundo o autor, são: a concepção insercional-competitiva [interesse do presente trabalho] e a concepção sustentável-solidária.

No âmbito de uma política de geração de trabalho e renda, a concepção insercionalcompetitiva apontada por França Filho (2006) preocupa-se com a questão da qualificação profissional de forma que se deve voltar as atenções para o acompanhamento das tendências de mercado, buscando atender às demandas reais de qualificação conforme as características e diferentes conjunturas de cada mercado de trabalho. Para o mesmo autor, esta concepção enfatiza a necessidade de organizar a economia informal numa perspectiva de inserção socioeconômica, disseminando os valores de empreendedorismo ligados a uma visão de negócio, tendo o dever de orientar os projetos a serem apoiados.

França Filho (2006) enfatiza que a concepção insercional-competitiva vê a inserção de desempregados e subempregados na economia de mercado como um meio de promoção do desenvolvimento, de forma que devem existir incentivos para que estes trabalhadores passem a atuar no mercado formal como micro e pequenos empreendedores. Esta política de geração de trabalho e renda deve ser pensada sob o enfoque de uma ótica inclusiva, uma vez que se busca a formalização do trabalho informal nos marcos institucionais regulatórios de uma economia de mercado (FRANÇA FILHO, 2006).

É comum os camelôs fazerem uso de espaços públicos onde há grande circulação de pessoas para que possam vender seus produtos que, normalmente, caracterizam-se por ser de preço relativamente baixo. Acerca deste comércio informal, Cleps $(2009$, p. 330) faz a seguinte explanação:

\footnotetext{
Dentro do comércio informal merecem destaque as feiras e mercados, principalmente os de artesanato e antiguidades que oferecem mercadorias diversificadas, criativas e inesperadas, o que os tornam mais atraentes. No entanto, há também aqueles que se dedicam à venda de mercadorias baratas, importadas, falsificadas entre outros. Caracterizamse por ocorrem em pontos localizados próximo a eventos esporádicos ou mesmo periódicos, sempre atraídos pelo fluxo de pessoas. Encontram-se também nos lugares de frequentes congestionamentos de tráfego ou mesmo nos semáforos das cidades.
}

Espaços públicos com atenção para as praças, calçadas e ruas, são os ambientes corriqueiramente mais utilizados pelos camelôs de rua para desempenharem suas atividades, 
devido sua localização, normalmente sendo partes privilegiadas de áreas centrais que contam com grande circulação de pessoas, possibilitando o comércio (KITAMURA; MIRANDA; RIBEIRO FILHO, 2007). No tocante a essas atividades ditas informais, "para os planejadores do espaço urbano, o comércio ambulante representa um entrave para a organização espacial das cidades [...]" (CLEPS, 2009, p. 333). Nesse sentido e devido à expansão dessas atividades, é imprescindível a criação de ambientes específicos para atuação desse grupo de trabalhadores, não apenas de forma a oferecer um espaço adequado para trabalharem, mas também no intuito de inseri-los no mercado de trabalho formal, tendo acesso a direitos e benefícios essenciais.

Montessoro (2006) salienta que uma das tentativas do poder público para acabar com o comércio informal nos espaços de uso comum da sociedade, como calçadas, praças e ruas, foi a construção dos camelódromos e dos shoppings populares. A autora conceitua esses espaços como sendo centros comerciais para ambulantes.

Transferir os camelôs das ruas para locais que comportem uma estrutura adequada para que possam desempenhar suas atividades é uma discussão bastante presente na atualidade, uma vez que é de interesse da administração pública, através das políticas urbanas, não apenas formalizar essas atividades, mas também reabilitar os espaços públicos ocupados de maneira indevida. Acerca disso, Jayme e Neves (2010, p. 611-612), mostram que:

\footnotetext{
As discussões contemporâneas sobre política urbana apontam para mudanças conceituais e metodológicas significativas no que se refere à reabilitação urbana, que passa a ser um instrumento de planejamento, com o papel de estabelecer a continuidade nos processos de apropriação dos espaços, incorporando as demandas físicas e sociais contemporâneas às referências simbólicas do passado e às potencialidades futuras, com um sentido de persistência temporal.
}

A preocupação dos formuladores de políticas públicas em formalizar o trabalho dos camelôs de rua demonstra o interesse da gestão pública em reduzir os índices de informalidade. Conforme Carrieri, Murta e Mendonça, et al. (2008), a atuação econômica anterior à transferência para os shoppings populares sofreu transformações que abrangem influências dos contornos de "formalização". Estas questões simbólicas perpassam estar ou não na rua, envolvendo a própria reorganização espacial do que antes eram atividades informais e agora se constituem como mercados formais, com sede fixa e legalizada.

\section{Resultados e discussões}

\subsection{Caracterização do Shopping Independência de Santa Maria-RS}

O Shopping Independência de Santa Maria-RS foi criado em 2010 com o intuito de tirar os camelôs da rua e atender a legislação adequada de um microempreendedor individual. Nesta ação, a Prefeitura Municipal de Santa Maria-RS teve o objetivo de criar condições de trabalho melhores para esta categoria, garantindo aos mesmos, conforto e segurança, bem como um plano de aposentadoria e demais benefícios garantidos pela Lei Complementar $\mathrm{n}^{\mathrm{o}} 128$ de 19 de dezembro de 2008.

$\mathrm{Na}$ estrutura do Shopping Independência de Santa Maria-RS, há capacidade para abrigar 208 bancas com dimensões de $2,00 \mathrm{~m}$ x 2,00m x 2,70m, sendo 106 encontradas no primeiro piso e 102 no segundo piso. Os aluguéis variam entre $\mathrm{R} \$ 118,00$ e $\mathrm{R} \$ 500,00$ e são cobrados com o objetivo da prefeitura fazer a manutenção do prédio, desde energia elétrica até a limpeza. O local abre todos os dias, sendo que de segunda a sábado funciona das $9 \mathrm{~h}$ às $21 \mathrm{~h}$, sem fechar ao meio dia e, nos domingos e feriados, o funcionamento ocorre das $11 \mathrm{~h}$ às $19 \mathrm{~h}$. 


\subsection{Análise descritiva do perfil do microempreendedor}

Os resultados da pesquisa mostram que, dentre os 47 respondentes, 14 pessoas são do sexo masculino e 33 do sexo feminino. A idade dos entrevistados varia de 15 a 69 anos, sendo o maior índice encontrado na faixa etária de 48 a 58 anos (31,92\%). Verificou-se também um percentual bastante elevado, 25,53\%, na faixa etária de 26 a 36 anos (Tabela 1 ).

Tabela 1 - Faixa etária dos entrevistados

\begin{tabular}{ccc}
\hline Faixa Etária & Número de Respondentes & Percentual (\%) \\
\hline $15-25$ & 7 & 14,89 \\
$26-36$ & 12 & 25,53 \\
$37-47$ & 7 & 14,89 \\
$48-58$ & 15 & 31,92 \\
$59-69$ & 6 & 12,77 \\
Total & 47 & 100,00 \\
\hline
\end{tabular}

Fonte: Elaboração própria.

Em relação à variável escolaridade, verifica-se que o maior número de microempreendedores possui ensino médio completo (51,07\%). Observa-se que apenas 2 entrevistados são analfabetos e somente um possui ensino superior completo (Tabela 2). Conforme Medeiros e Salm (1994), o grau de escolaridade é apontado na literatura nacional como uma condição para inserção no mercado de trabalho formal, seja em que posto for. O baixo nível de escolaridade pode ser usado para explicar as altas taxas de informalidade, mas o que se observa no presente estudo, é que a grande maioria dos antigos camelôs de rua possui um nível mínimo de instrução, tendo ensino médio completo ou pelo menos ensino fundamental completo $(19,15 \%)$.

Tabela $2-\mathrm{N}$ ível de esco laridade dos entrev istados

\begin{tabular}{ccc}
\hline Nível de Escolaridade & Número de Respondentes & Percentual (\%) \\
\hline Analfabeto & 2 & 4,25 \\
Ensino Fundamental & 5 & 10,64 \\
Incompleto & & \\
Ensino Fundamental & 9 & 19,15 \\
Completo & 4 & 8,51 \\
Ensino Médio Incompleto & 24 & 51,07 \\
Ensino Médio Completo & 2 & 4,25 \\
Ensino Superior Incompleto & 1 & 2,13 \\
Ensino Superior Completo & 47 & 100,00 \\
Total & & \\
\hline
\end{tabular}

Fonte: Elaboração própria.

\subsection{Análise descritiva do empreendimento}

Os dados revelam que a maior parte dos empreendimentos tem idade ativa de 1 a 20 anos e os mais antigos, cerca de 40 anos. Observa-se uma grande variedade com relação aos produtos vendidos, os quais vão desde eletrônicos e brinquedos, até itens de artesanato e ervas medicinais. A grande maioria vende eletrônicos em função da maior lucratividade. É interessante destacar que grande parte das bancas não vende apenas um produto específico, mas sim, uma diversidade.

Verificou-se que 35 bancas não possuem funcionários e apenas 12 delas possuem, sendo que destes, apenas um possui carteira assinada. Geralmente os funcionários trabalham apenas em finais de semana, período em que os proprietários costumam viajar para comprar produtos. 
Os resultados relativos à receita bruta mensal auferida mostram que 27,66\% dos respondentes auferem uma receita que varia de $\mathrm{R} \$ 1.000,00$ a $\mathrm{R} \$ 1.999,00$. Destaca-se que $25,53 \%$ não souberam responder acerca de sua receita bruta. Este fato decorre de que a grande maioria dos empreendimentos não faz um controle financeiro adequado sobre o fluxo de entrada e saída de dinheiro, e também em função de que alguns dos entrevistados são apenas funcionários e não têm acesso a estas informações.

Somente $12,77 \%$ dos respondentes declararam auferir uma receita bruta mensal que varia entre $\mathrm{R} \$ 100,00$ a $\mathrm{R} \$ 999,00$. Esse nível de receita foi o menor valor encontrado em função de que estes empreendimentos geralmente vendem produtos de preço mais baixo, como artesanato, brinquedos, produtos de bazar e ervas medicinais. A maior receita bruta está entre $\mathrm{R} \$ 6.000,00$ e $\mathrm{R} \$ 6.999,00$ sendo também a menor categoria encontrada, em torno de $2,13 \%$ dos respondentes (Figura 1).

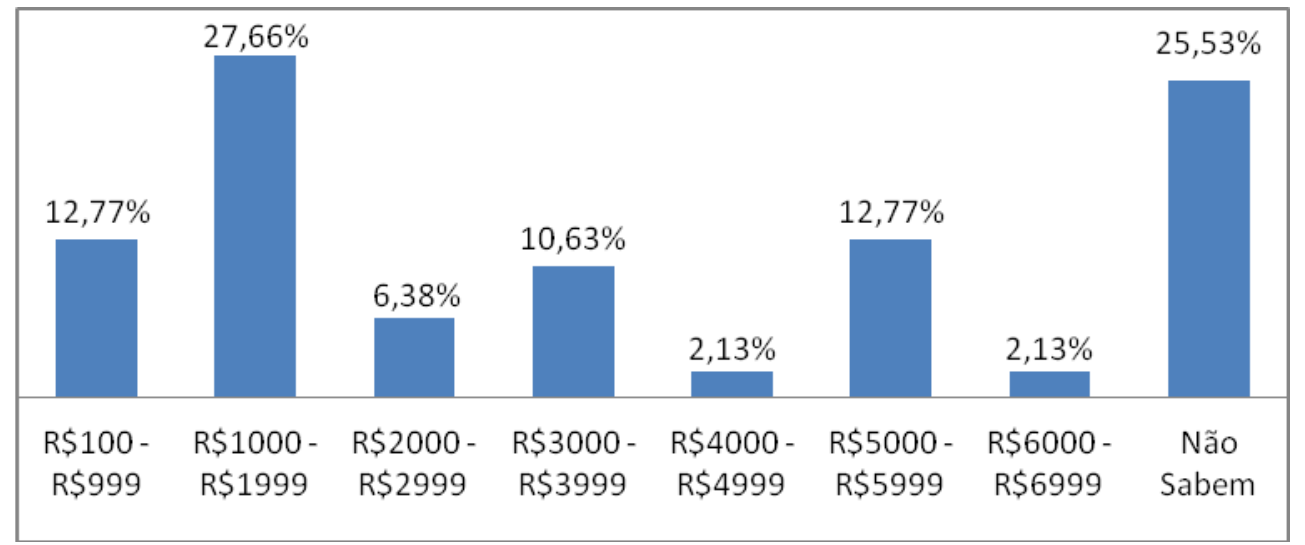

Figura 1 - Receita bruta mensal auferida pelos empreendimentos

Fonte: Autoria dos autores.

Acerca da receita bruta mensal auferida, os resultados mostram que a mesma varia de acordo com o tipo de produto vendido no empreendimento. Aqueles que apresentam maior receita bruta são normalmente os que vendem eletrônicos e variedades, produtos de valor mais elevado no mercado se comparados aos demais.

Referente à satisfação com o local onde trabalham, em uma escala de 0 a 10 , sendo 0 totalmente insatisfeito e 10 totalmente satisfeito, a grande maioria, 25,53\% dos respondentes, atribuiu nota 7 ao Shopping, seguido dos que atribuíram nota 8, 23,40\%. A nota mínima atribuída foi 4, por 4,26\% dos entrevistados (Figura 2).

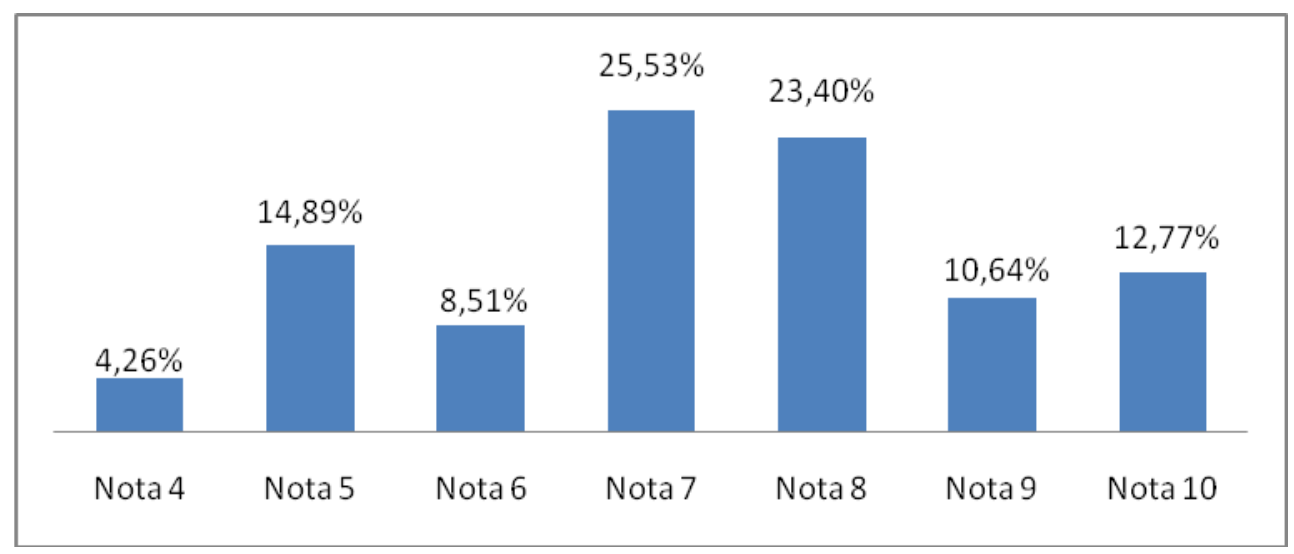

Figura 2 - N ota atribu ída à satisfação com o M E I

Fonte: Autoria dos autores. 
Quando questionados em relação à satisfação com o MEI, 62,00\% dos respondentes afirmam não estar satisfeitos com o mesmo. Isso se deve ao fato de os custos terem aumentado principalmente devido ao pagamento de aluguel e de as vendas terem diminuído devido à falta clientes. Consequentemente, também houve uma redução da renda individual auferida pelos microempreendedores se comparada com a renda individual que auferiam quando eram vendedores de rua.

Por fim, analisou-se também a qualidade de vida dos empreendedores. O objetivo da análise desta variável foi identificar as mudanças que ocorreram na qualidade de vida dos microempreendedores após a implantação do MEI. Conforme a Figura 3, após o MEI, 51,00\% dos entrevistados respondeu que houve melhora nesse aspecto, pois passaram a trabalhar em ambiente fechado e climatizado, não mais expostos ao tempo e a pragas urbanas, situações com as quais se deparavam na rua. Uma minoria respondeu que sua qualidade de vida piorou devido à redução na renda e os demais, 38,00\%, afirmaram que a qualidade de vida permaneceu a mesma.

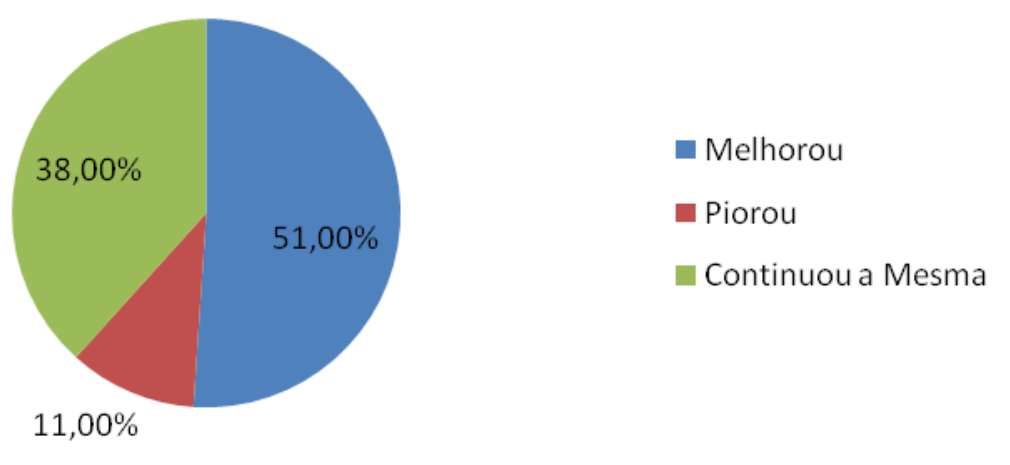

Figura 3 - Nota atribuída à satisfação com o MEI

Fonte: Autoria dos autores.

\section{Considerações finais}

Apesar da integração ao programa MEI, por meio da qual os empreendedores passaram a ser trabalhadores legalmente formalizados, houve o aumento de custo e redução da receita bruta. Em função disto, conclui-se que os microempreendedores individuais encontram-se, em sua maioria, insatisfeitos com sua ida para o Shopping Independência. A falta de visibilidade para os produtos foi outro fator ponderado pelos entrevistados como um dificultador. Entre os fatores positivos são citados a limpeza, a organização e a segurança.

Por outro lado, após a implementação do MEI a qualidade de vida dos microempreendedores melhorou, pois passaram a trabalhar em um ambiente com estrutura mais adequada que proporciona melhores condições de trabalho a esta categoria. Sugere-se maior divulgação do Shopping, principalmente do segundo piso, pois grande parcela da população não sabe da sua existência, para que desta forma seja possível aumentar as vendas.

Outra constatação é que a iniciativa da Prefeitura Municipal de Santa Maria-RS contribuiu para reduzir uma parcela do trabalho informal na cidade, pois fez com que estes trabalhadores, que antes não tinham nenhum tipo de auxílio ou aparato legal para realizarem seu trabalho, passassem a integrar o MEI, tendo seus direitos assegurados e sendo protegidos pela legislação aplicada a esta categoria. 


\section{Referências}

APPOLINÁRIO, F. Metodologia da ciência: filosofia e prática da pesquisa. São Paulo: Pioneira Thomson Learning, 2006.

BAGNASCO, A. A economia informal. Ensaios FEE, v. 18, n. 2, p. 13-31, 1997.

BRASIL. Lei Complementar n. 128, de 19 de dezembro de 2008. Cria a figura do Microempreendedor Individual - MEI e modifica partes da Lei Geral da Micro e Pequena Empresa (Lei Complementar 123/2006). Diário Oficial [da] República Federativa do Brasil, Brasília, DF, 22 dez. 2008.2 Disponível em: <http://www.planalto.gov.br/ccivil_03/Leis/LCP/Lcp128.htm>. Acesso em: 28 mai. 2014.

BRASIL. Portal do Empreendedor. MEI: Microempreendedor Individual. 2013. Disponível em: $<$ http://www.portaldoempreendedor.gov.br/mei-microempreendedor-individual $>$. Acesso em: 5 dez. 2013.

CACCIAMALI, M. C. Globalização e processo de informalidade. Economia e Sociedade, Campinas, v. 9, n. 1 (14), p. 153-174, jun. 2000.

CARRIERI, A. P. de; MURTA, I. B. D. ; MENDONÇA, M. C. N. ; MARANHÃO, C. M. S. A. de; SILVA, A. R. L. da. Os espaços simbólicos e a construção de estratégias no Shopping Popular Oiapoque. Cadernos EBAPE.BR, v. 6, n. 2, p. 1-13, jun. 2008.

CLEPS, G. D. G. Comércio informal e a produção do espaço urbano em Uberlândia (MG). Revista Sociedade e Natureza, Uberlândia, v. 21, n. 3, p. 327-339, dez. 2009.

CORSEUIL, C. H.; REIS, M. C.; BRITO, A. S. Critérios de classificação para ocupação informal: consequências para a caracterização do setor informal e para a análise do bem-estar social no Brasil. Brasília: Rio de Janeiro: IPEA, 2013. (Texto para Discussão, 1.879).

FRANÇA FILHO, G, C. de. Políticas públicas de economia solidária no Brasil: características, desafios vocação. 2006.2 Disponível em: <http://www.dmtemdebate.com.br/abre_artigos.php?id=19>. Acesso em: 28 jun. 2014.

KITAMURA, C. K.; MIRANDA, M.; RIBEIRO FILHO, V. O comércio e serviços ambulantes: uma discussão. Caminhos de Geografia - revista online, Uberlândia, v. 8, n. 23, p. 20-26, 2007. Disponível em: <http://www.seer.ufu.br/index.php/caminhosdegeografia $>$. Acesso em: 2 jul. 2014.

GIL, A. C. Métodos e técnicas de pesquisa social. 6. ed. São Paulo: Atlas, 2008.

JAYME, J. G.; NEVES, M. A. de. Cidade e espaço público: política de revitalização urbana em Belo Horizonte. Caderno CRH, Salvador, v. 23, n. 60, p. 605-617, set./dez. 2010. 
MEDEIROS, C. A.; SALM, C. O mercado de trabalho em debate. Revista Novos Estudos, n. 39, p. 49-65, jul. 1994.

MONTESSORO, C. Centralidade urbana e comércio informal: os novos espaços de consumo no centro de Anápolis. 2006. 398 f. Tese (Doutorado em Geografia) - Universidade Estadual Paulista, Presidente Prudente, 2006.

ORGANIZAÇÃO INTERNACIONAL DO TRABALHO (OIT). A OIT e a Economia Informal. Lisboa, 2006.

SERVIÇO DE APOIO ÀS MICRO E PEQUENAS EMPRESAS (SEBRAE). Empreender é ter vontade e oportunidade. 2014 . Disponível em: $<$ http://gestaoportal.sebrae.com.br/momento/quero-melhorar-minha-empresa/comece-porvoce/empreendedorismo>. Acesso em: 10 abr. 2014.

THEODORO, M. As bases da política de apoio ao setor informal no Brasil. Brasília: IPEA, 2000. (Texto para Discussão, 762).

ULYSSEA, G. Informalidade no mercado de trabalho brasileiro: uma resenha da literatura. Revista de Economia Política, v. 26, n. 4 (104), p. 596-618, out./dez. 2006. 